\title{
Application of big BAF sampling for estimating carbon on small woodlots
}

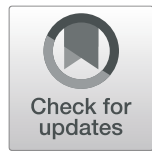

\author{
Yingbing Chen ${ }^{1 *} \mathbb{D}$, Ting-Ru Yang ${ }^{1}$, Yung-Han Hsu', John A. Kershaw Jr and Dale Prest ${ }^{2}$
}

\begin{abstract}
Background: To accurately and efficiently quantify forest carbon stocks, a good forest inventory using appropriate sampling that minimizes costs and human effort is needed for landowners who want to enter carbon offset markets. The most commonly used sampling unit is the fixed-area plot; however, it is time consuming, expensive, and is often less accurate than variable probability methods when resources are limited. Previous studies show that big BAF sampling is efficient at estimating volume, therefore, it is interesting to explore whether the efficiency can be extended to carbon. The study is conducted at Noonan Research Forest, which located $30 \mathrm{~km}$ northwest of Fredericton, New Brunswick, Canada. In this study, we compared count BAF effects and measure BAF effects on the overall sampling outcome and sampling error for total aboveground $C$ and each C component (wood, bark, branches, and foliage) and explored the minimum sample size requirements and costs for different combinations of count and measure BAFs.

Results: From our research, we found that the efficiency gained from estimating volume using big BAF sampling can be extended to carbon estimation. The minimum overall inventory cost from this study is $\$ 3500$ Canadian, compared to a full Noonan inventory costs of $\$ 40,000$ with $2 \%$ standard error. We also found that, similar to volume, count BAF has a larger effect on carbon estimation than measure BAF and the optimum choice of measure BAF depends on the choice of count BAF. The optimal count BAF and measure BAF combination for Noonan Research Forest was 2/24.

Conclusion: Our results show that big BAF sampling was a very efficient sampling design for estimating carbon and significantly reduces overall inventory costs. Although big BAF sampling is not widely used in forest inventory, it should be considered by landowners facing the cost constraint barrier for entering carbon market and seeking a cost-effective inventory system for estimating carbon.
\end{abstract}

Keywords: Forest inventory, Above ground carbon stocks, Horizontal point sampling, Subsampling, Inventory costs

\section{Introduction}

Forests are globally significant carbon $(\mathrm{C})$ pools, and can be managed to sequester additional atmospheric C. Approximately $60 \%$ of terrestrial $\mathrm{C}$ is estimated to be stored in forest ecosystems (Elias and Potvin 2003). One of the widely-used indicators of forest ecosystem $\mathrm{C}$ is aboveground forest biomass (Case and Hall 2008). To estimate this aboveground forest biomass, a forest inventory is needed to collect relevant data. With all forest inventories, there is a need for accurate and precise estimates that are balanced by a need to be cost efficient (Kershaw et al. 2016) Therefore, a good forest inventory of

\footnotetext{
* Correspondence: ychen22@unb.ca

${ }^{1}$ Faculty of Forestry and Environment Management, University of New

Brunswick, PO Box 4400, Fredericton, NB E3B 5A3, Canada

Full list of author information is available at the end of the article
}

aboveground forest biomass using appropriate sampling that yields reliable estimates with minimal costs and human effort is essential for better quantifying forest $\mathrm{C}$ stocks (Ravindranath and Ostwald 2008).

The most commonly used sampling methods for carbon projects are simple random sampling, stratified random sampling, or systematic sampling with rectangular or square shaped fixed area sample plots (Brown 1999, 2002; Ravindranath and Ostwald 2008). Very few carbon inventories actually measure carbon content directly (Brown 2002) and, instead, rely on common individual tree measurements (such as diameter and height) and allometric equations (Brown 1999; Lambert et al. 2005; Heath et al. 2009). The use of allometric equations reduces the task of carbon estimation to a standard forest inventory where the main concerns are: how many 
sample points; how these sample points are located across the area of interest; what types of sample units to use; what tree attributes to measure and record; and whether or not to apply hierarchical or subsampling selection schemes (Kershaw et al. 2016).

The use of fixed-area plots has a long history in forest inventory and forest monitoring (Iles 2003; Kershaw et al. 2016), and has been advocated as the preferred method for carbon estimation and monitoring (Brown 1999, 2002). Using fixed area plots to collect data is relatively straight forward, and can be easily applied to standing trees and other materials in the forest (Kershaw et al. 2016). Other reasons for preferring fixed area plot sampling in forest projects include: 1) fixed area plots are suitable for both large plots and small plots; 2) easy to draw their boundaries for periodical and long-term monitoring; and 3) easy to record GPS readings for subsequent remeasurement and monitoring (Ravindranath and Ostwald 2008). However, measurement of all trees in a sample plot using fixed-area plot sampling is expensive and time consuming, even with the most advanced measurement technology (Rice et al. 2014). In addition, Rice et al. (2014) showed that challenges such as errors in stem tallies and in establishing plot boundaries may contribute to bias in fixed area sampling, and the desired accuracy or precision may not be achieved even without these field errors. Thus, a more efficient method of collecting field measurements is needed to improve accuracy, and minimize costs and human errors.

Horizontal point sampling (HPS) samples trees proportional to their basal area at breast height (DBH). In HPS, a horizontal angle is projected and rotated $360^{\circ}$ about plot center. Trees that are larger than the projected angle are tallied as "in" trees. Because of the sampling geometry, basal area (BA) per unit area is estimated by multiplying the count of "in" trees by the basal area factor (BAF). The ability to estimate BA by counting trees rather than measuring all the tree diameters makes HPS a very efficient sampling scheme since BA is closely correlated with other forest attributes of interest such as volume, biomass, and C (Kershaw et al. 2016).

Big BAF sampling is a subsampling modification of HPS (Iles 2003; Marshall et al. 2004), which is aimed at improving the efficiency and accuracy of HPS while reducing measurement costs. Two angle gauges are used in big BAF sampling: a small angle gauge is used to select count trees and estimate BA per unit area (count BAF); then a larger BAF angle gauge is used to select trees for detailed measurement of volume or other attributes of interest (measure BAF). These measure trees are used to estimate the ratio between volume and/or other attributes (such as biomass or $\mathrm{C}$ ) and basal area (XBAR, where $\mathrm{X}$ denotes volume or any other attribute of interest) (Iles 2003;
Marshall et al. 2004; Kershaw et al. 2016). Because the variation in count trees between sample points is much larger than the variation in XBAR, big BAF sampling allocates more efforts to counting trees (i.e., more sample points) rather than to measuring trees which leads to time and cost savings (Marshall et al. 2004; Yang et al. 2017). Therefore, only a small portion of trees across the entire sample, selected using a larger BAF angle gauge, needs to be measured.

Quantifying the effects of count BAF (cBAF) and measure BAF (mBAF) on sampling outcomes is essential for making informed design decisions when using big BAF sampling (Yang et al. 2017). Yang et al. (2017) explored the interactions between count BAF (cBAF) and measure BAF (mBAF) on overall sampling error, minimum sample size requirements, and costs in a mixed species forest structure in northeastern North America, and found that the choice of cBAF had a bigger impact on both overall sampling error and minimum sample size requirements than did the choice of $\mathrm{mBAF}$ when coefficients of variation of VBAR (CV (VBAR)) were low. The wide range of choice for mBAF at low CV (VBAR) can save substantial inventory investment by choosing a larger mBAF, since the cost of measuring trees is higher than counting trees. However, when $\mathrm{CV}$ (VBAR) increased, choice of mBAF became increasingly important and more measure trees were required (Yang et al. 2017). Yang et al.'s (2017) work also showed that trade-offs between cBAF and mBAF became increasingly important as inventory resources became more limiting.

In the eastern Canadian provinces of New Brunswick and Nova Scotia, almost half of the forested land is in small private ownership. Given the current low markets for pulpwood and sawlog material, small private landowners are looking for alternative markets for their forest products. The potential offered by monetized carbon offset programs is large, and may help prevent the conversion of forested land to other uses and/or the abandonment of forest management by small private woodlot owners. Monetized carbon markets, in addition to potentially helping to slow the rates of anthropogenic climate change, offers forest land owners a new potential market for their forest products. However, the requirements for an Improved Forest Management project under a monetized offset program are often beyond the financial ability of individual small private woodlot owners. Russell-Roy et al. (2014) estimated costs of developing a compliance market oriented Improved Forest Management project on 391 ha of forest-land in Vermont at USD $\$ 78,650$ for project development alone. The estimated costs of a forest field inventory under this same scenario was USD \$12,903 for the same 391 ha, with inventories required to be updated every 10-12 years throughout the 100-year project timeline. Additional costs 
beyond those above were also identified in the same study, highlighting the considerable cost barriers that small landowners face in accessing carbon offset markets. Big BAF sampling for $\mathrm{C}$ might be one way to potentially reduce the costs associated with the forest field inventories required at project initiation and throughout the additional verification events, required every $10-12$ years throughout the project lifetime.

To best apply big BAF sampling in carbon inventories, it is important to explore whether the efficiency gained from VBAR can be extended to the carbon: basal area ratio (CBAR) and to quantify the interactions between cBAF and mBAF on overall sampling error, sample size requirements, and costs. The objectives of this study were 1) explore the impact of CBAR on sampling outcomes for both total $\mathrm{C}$ and $\mathrm{C}$ by component; 2 ) explore the impact of the choice of $\mathrm{cBAF}$ and $\mathrm{mBAF}$ on overall sampling error; 3 ) explore minimum sample size requirements and costs for different count and measure BAF combinations to determine optimum combinations.

\section{Methods}

\section{Study site}

This study was conducted in the Noonan Research Forest (NRF, N 45 59'12'', W $66^{\circ} 25^{\prime} 15^{\prime \prime}$ ), a 1531-ha forest located $30 \mathrm{~km}$ northwest of Fredericton, New Brunswick, Canada. Since 1985, the forest is managed by The University of New Brunswick. In 2002, a total of 296 stands were delineated on the NRF, of which 38 stands were considered non- forested stands and 19 stands were recently harvested. Hardwood, mixed and softwood stands compose the remaining 239 stands. These stands all originated following land clearing and fire in the 1920s.

A permanent $100 \mathrm{~m}$ by $100 \mathrm{~m}$ inventory grid was overlaid on the NRF in a north-south, east-west orientation (Fig. 1). In this study we used random selection within stand polygons, and 3 grid intersections per stand were randomly selected. In stands with 3 or less grid intersections, all grid intersections within that stand were selected. A total of 705 sample points was selected (approximately 1 point per $2 \mathrm{ha}$ ), and all data were collected in the summer and early fall of 2002 using a $2 \mathrm{M}$ basal area factor angle gauge (i.e., each tally tree represented $2 \mathrm{~m}^{2} \cdot \mathrm{ha}^{-1}$ of basal area).

Diameter at breast height (DBH, nearest $0.1 \mathrm{~cm})$, distance from sample point to tree center (DIST, $0.1 \mathrm{~m}$ ), and species were recorded for each count "in" tree. Total height (TOTHT, nearest $0.1 \mathrm{~m}$ ) was measured on a subsample of up to three trees per species per plot. For each species the diameter distributions were divided into thirds and one tree selected from each third. Species-specific height-diameter equations were derived from the subsampled heights and total height for all trees estimated. A total of 8518 trees were tallied and 4572 trees were selected for height measurement.

The BAF at which trees become borderline (maxBAF) for all trees was calculated using measured DBH and DIST:

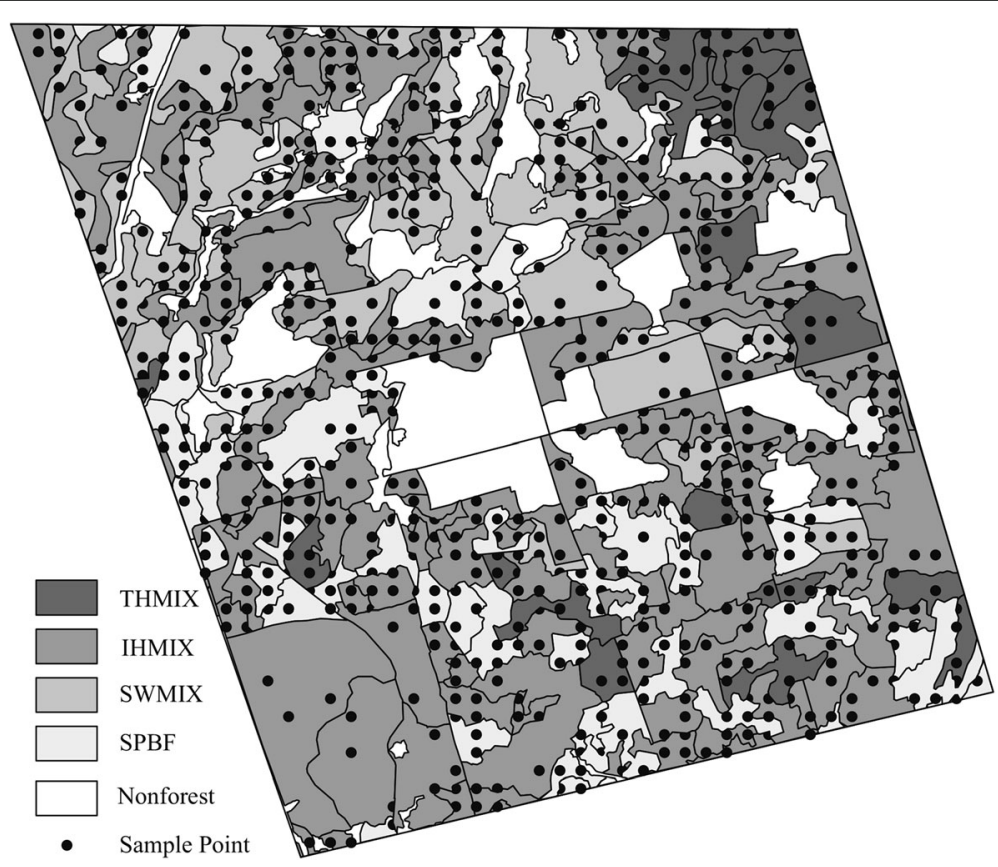

Fig. 1 Map of Noonan Research Forest showing stand polygons by forest type and sample point locations 


$$
\operatorname{maxBAF}=\left(\frac{\mathrm{DBH}}{2 \cdot \mathrm{DIST}}\right)^{2}
$$

and used in the sample simulations to quickly determine if trees were "in" or "out" for a given BAF (see Yang et al. (2017) for more details).

\section{Carbon estimation}

To estimate aboveground Carbon (C) storage, aboveground biomass (AGB) needs to be estimated first using allometric equations (Elias and Potvin 2003). Using Lambert et al.'s (2005) Canadian biomass equations, aboveground biomass was estimated by four components/pools (stem wood, stem bark, leaf, and branches) for each tree. Total biomass was calculated by summing across the four components. Total $\mathrm{C}$ and $\mathrm{C}$ by component $(\mathrm{kg})$ were estimated using the species-specific conversion factors from Lamlom and Savidge (2003) for each tree. The carbon to basal area ratio $\left(\mathrm{kg} \cdot \mathrm{m}^{-2}\right)$ for total, stem wood, stem bark, branch, and leaf, were calculated by dividing the estimated $\mathrm{C}$ component by tree basal area:

$$
\mathrm{XCBAR}_{i}=\frac{C_{\mathrm{X}, i}}{\mathrm{BA}_{i}}=\frac{C_{\mathrm{X}, i}}{0.00007854 \times \mathrm{DBH}_{i}^{2}}
$$

where $\mathrm{XCBAR}_{i}=$ the carbon to basal area ratio of the $\mathrm{X}$ carbon component (total, stem wood, stem bark, leaf or branches) for the $i$ th sample tree $\left(\mathrm{kg} \cdot \mathrm{m}^{-2}\right) ; C_{\mathrm{X}, i}=$ estimated $\mathrm{X}$ carbon component (total, stem wood, stem bark, leaf or branches) for the $i$ th sample tree $(\mathrm{kg}) ; \mathrm{BA}_{i}$ $=$ the basal area of the $i$ th sample tree $\left(\mathrm{m}^{2}\right) ; \mathrm{DBH}_{i}=$ the measured diameter at breast height of the $i$ th sample tree $(\mathrm{cm})$.

\section{Big BAF sample simulation}

The 705 plots collected in the original complete inventory of NRF were used here to simulate smaller sample sizes. Sample plots were selected using simple random sampling, and 250 replicate sample simulations were generated with different fixed sample sizes ranging from 20 to 100 in steps of 10 and from 100 to 200 in steps of 50. Count BAFs (cBAF) ranged from 2 to $30 \mathrm{M}$ in steps of 2 and measure BAFs (mBAF) ranged from 4 to $100 \mathrm{M}$ in steps of 4 . Only combinations where $\mathrm{mBAF} \geq \mathrm{cBAF}$ were used and all allowable combinations of $\mathrm{CBAF} \times$ mBAF were simulated on each sample point selected in each replicate sample simulation. Count and measure trees were determined using maxBAF, if maxBAF was greater than or equal to cBAF, then the tree was considered "in" for that sample point and cBAF. Likewise, measure trees were those trees that had a maxBAF that was greater than or equal to a given mBAF.

\section{Data analyses}

To explore the influence of $\mathrm{cBAF}$ and $\mathrm{mBAF}$ on sampling outcomes on total $\mathrm{C}$ and different $\mathrm{C}$ components, trends were evaluated across the range of cBAFs and mBAFs. For each sample combination $(\mathrm{cBAF} \times \mathrm{mBAF} \times$ sample replicate), average basal area per hectare $\left(\mathrm{m}^{2} \cdot \mathrm{ha}^{-1}\right)$ was estimated using:

$$
\overline{\mathrm{BA}}=\frac{\sum_{i=1}^{N}\left(g_{i} \times \mathrm{cBAF}\right)}{N}
$$

where $\overline{\mathrm{BA}}$ is the average basal area $\left(\mathrm{m}^{2} \cdot \mathrm{ha}^{-1}\right) ; g_{i}$ is the number of count trees on the $i$ th sample point; cBAF is the count BAF; $N$ is the number of sample plots. The mean XCBAR was calculated by averaging the individual tree XCBARs across all measure trees in the sample (mean ratio estimator):

$$
\begin{aligned}
\mathrm{XC} \overline{\mathrm{BAR}} & =\frac{\sum_{m=1}^{M} \mathrm{XCBAR}_{m}}{M} \\
& =\left(\frac{1}{M}\right) \sum_{m=1}^{M}\left(\frac{\mathrm{XC}_{m}}{\mathrm{BA}_{m}}\right) \\
& =\left(\frac{1}{M}\right) \sum_{m=1}^{M}\left(\frac{\mathrm{XC}_{m}}{0.00007854 \times \mathrm{DBH}_{m}^{2}}\right)
\end{aligned}
$$

where $\overline{X C B A R}$ is the carbon: basal area ratio of the $X$ th $\mathrm{C}$ component for the $m$ th measure tree $\left(\mathrm{kg} \cdot \mathrm{m}^{-2}\right)$; $M=$ the total number of measure trees in the sample; $\mathrm{XC}_{m}=$ the content of the $X$ th $\mathrm{C}$ component in the $m$ th measure tree $(\mathrm{kg}) ; \mathrm{BA}_{m}=$ the basal area of the $m$ th measure tree $\left(\mathrm{m}^{2}\right)$; and $\mathrm{DBH}_{m}=$ the $\mathrm{DBH}$ of the $m$ th measure tree $(\mathrm{cm})$. Average $\mathrm{C}$ per ha $\left(\mathrm{kg} \cdot \mathrm{ha}^{-1}\right)$ by $\mathrm{C}$ component is then obtained by multiplying each $\overline{X C B A R}$ by $\overline{B A}$ :

$$
\overline{\mathrm{XC}}=\mathrm{XC} \overline{\mathrm{BAR}} \times \overline{\mathrm{BA}}
$$

Bruce's formula (Goodman 1960; Yang et al. 2017) was used to estimate percent sampling error for each $\mathrm{C}$ component for each sample combination:

$$
s e \%(\overline{X C})=\sqrt{s e \%^{2}(\text { Counts })+s e \%^{2}(X C B A R)}
$$

where,

$$
\operatorname{se} \%(\bar{Y})=100\left(\frac{S_{\bar{Y}}}{\bar{Y}}\right)=100\left(\frac{S}{\sqrt{n}}\right)\left(\frac{1}{\bar{Y}}\right)=\frac{\mathrm{CV}(\bar{Y})}{\sqrt{n}}
$$

where $\bar{Y}$ is either Counts or XCBAR, $S_{\bar{Y}}$ is the associated standard error, $S$ is standard deviation; $\mathrm{CV}(\bar{Y})=$ coefficient of variation; and $n=$ sample size (Note that while $\mathrm{se}(\overline{\mathrm{BA}})>\mathrm{se}($ Counts), se $\%$ (Counts) $=\mathrm{se} \%(\overline{\mathrm{BA}})$ because 
Count and BA differ only by the constant BAF, which appears in both the numerator and denominator of eq. 7).

The "true" or "best" value of $\overline{X C}$ (denoted as $\widehat{X C}$ ) was assumed to be the normal horizontal point sample average based on $\mathrm{cBAF}=2$ and all trees measured (i.e., $\mathrm{mBAF}=2$ ) across the 705 sample points. $\widehat{X C}$ and its associated standard error $(s e \%(\widehat{X C}))$ were compared to the estimates of $\overline{X C}$ and se $\%(\mathrm{XC})$ by $\mathrm{cBAF}$ and mBAF using beanplots (Kampstra 2008) and other graphical methods.

\section{Sample size and sample cost estimation}

Using the sampling results, a nonlinear mixed effects model was fit to predict $s e \%(\overline{X C})$ as a function of sample size (Yang et al. 2017):

$$
\mathrm{se} \%(\overline{\mathrm{XC}})=b_{0}\left(\frac{1}{n^{b_{1}}}\right)
$$

with random effects for $\mathrm{CBAF}$ and $\mathrm{mBAF}$ nested within cBAF fitted for both $b_{0}$ and $b_{1}$. Using the random effects, the variance contributions associated with $\mathrm{CBAF}$ and mBAF were estimated for each $C$ component. The minimum samples sizes required for $10 \%$ error were then estimated for each $\mathrm{C}$ component over the range of cBAF and mBAF.

Yang et al. (2017) outlined methods for determining costs associated with big BAF sampling and their methods were used here to estimate inventory costs associated with the various $\mathrm{C}$ components and combinations of cBAF and mBAF. Yang et al.'s (2017) cost equation was:

$$
\begin{aligned}
\text { Cost }_{\text {Total }}= & \text { Cost }_{\text {Overhead }} \\
& +n\left(\operatorname{Cost}_{\mathrm{Est}}+k\left(\frac{\overline{\mathrm{BA}}}{\mathrm{cBAF}}\right)\right) \\
& +r \times n\left(\frac{\overline{\mathrm{BA}}}{\mathrm{mBAF}}\right)+w \sqrt{n \times A}
\end{aligned}
$$

where Cost $_{\text {Overhead }}=$ the costs of planning the forest inventory; Cost $_{\mathrm{Est}}=$ the costs associated with plot establishment, $k=$ the costs of a count tree determined, species identified and DBH measured; $r=$ costs to measure tree height, $w=$ travel costs between sample points (dollars per $\mathrm{m}$ travelled). Assuming a two-person crewday costs $\$ 650.00$ Canadian, and using the time-motion values reported by Yang et al. (2017), the coefficients in eq. 9 were as follows: Cost $_{\text {Overhead }}=\$ 1300.00$ (assumed 2 days for planning); Cost $_{\mathrm{Est}}=\$ 2.70 ; k=\$ 0.765 ; r=\$ 4.41$; and $w=\$ 0.0945$. Using these values and the minimum sample sizes estimated from Eq. 8, total inventory costs were calculated. Design effects, defined as the relative efficiency of sample design 1 versus sample design 2
(Särndal et al. 1992), were calculated as the ratio of costs of the two sample designs:

$$
D E_{1,2}=\frac{\text { Cost }_{1}}{\text { Cost }_{2}}
$$

If $\mathrm{DE}<1$, then sample design 1 is more efficient than sample design 2 . In this study, sample design 1 and 2 are various $\mathrm{CBAF}$ and $\mathrm{mBAF}$ combinations.

\section{Results}

\section{Coefficients of variation}

Figure 2 shows coefficients of variation $(\mathrm{CV})$ for count BAF (cBAF) and the various carbon:basal area ratios (CBAR) by basal area factor (BAF). As expected, the CV for counts increased rapidly with increasing cBAF. The CBARs, on the other hand, were relatively constant over the range of mBAF. Total CBAR averaged just above $20 \%$ while wood and bark CBARs averaged about 25\% across all mBAFs explored in this study. Branch and leaf CBARs were more variable, averaging about $42 \%$, but also independent of mBAF.

\section{Carbon estimates}

The average total aboveground live tree carbon $\left(\mathrm{kg} \cdot \mathrm{ha}{ }^{-1}\right)$ based on the field data was $40,046.39 \mathrm{~kg} \cdot \mathrm{ha}^{-1}( \pm 16.5 \%$ CV). Wood C was $27,824.40 \mathrm{~kg} \cdot \mathrm{ha}^{-1}( \pm 16.6 \% \mathrm{CV})$, Bark $\mathrm{C}$ was $4126.37 \mathrm{~kg} \cdot \mathrm{ha}^{-1}( \pm 16.9 \% \mathrm{CV})$, Branch $\mathrm{C}$ was $6002.55 \mathrm{~kg} \cdot \mathrm{ha}^{-1}( \pm 18.7 \% \mathrm{CV})$, and Leaf $\mathrm{C}$ was 2093.07 $\mathrm{kg} \cdot \mathrm{ha}^{-1}( \pm 18.8 \% \mathrm{CV})$. Bias was minimal for total carbon across most combinations of cBAF, mBAF, and sample size (Fig. 3). From Fig. 3, it can be seen that variation in carbon estimates increased with increasing $\mathrm{cBAF}$, but remained more or less constant with increasing $\mathrm{mBAF}$. As expected, increasing sample size decreased sample error (Fig. 3). Similar to the results of total carbon, variation increased with increasing $\mathrm{cBAF}$ for all carbon components (Fig. 4). For the wood, bark, and branch components, bias increased with increasing cBAF but generally remained small (less than about $6 \%$ overall).

\section{Sample size effects}

Table 1 shows the fixed effect parameter estimates and associated regression statistics for Eq. 8. The full model with all random effects accounted for $84 \%$ of the variation in $\% \mathrm{SE}$, with the fixed effects component accounting for $64 \%$. Random effects associated with the $b_{1}$ parameter were quite small, though significant $(p<0.05)$ cBAF accounted for an additional $22 \%$ of the variation in SE\% while mBAF within cBAF only accounted for $1 \%$ of the variation. CBAF had a larger effect on percent standard error than did mBAF (Fig. 5). Similar results were 


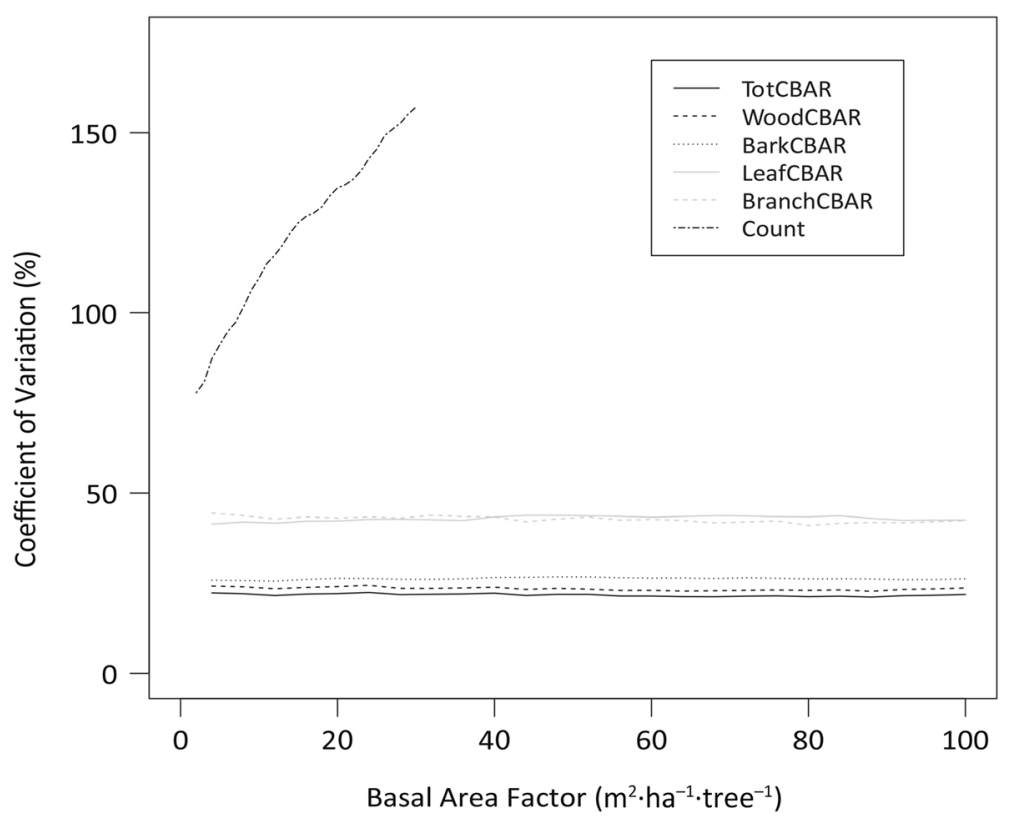

Fig. 2 Coefficients of variation for count BAF and for each carbon component: basal area ratio (XCBAR) by basal area factor

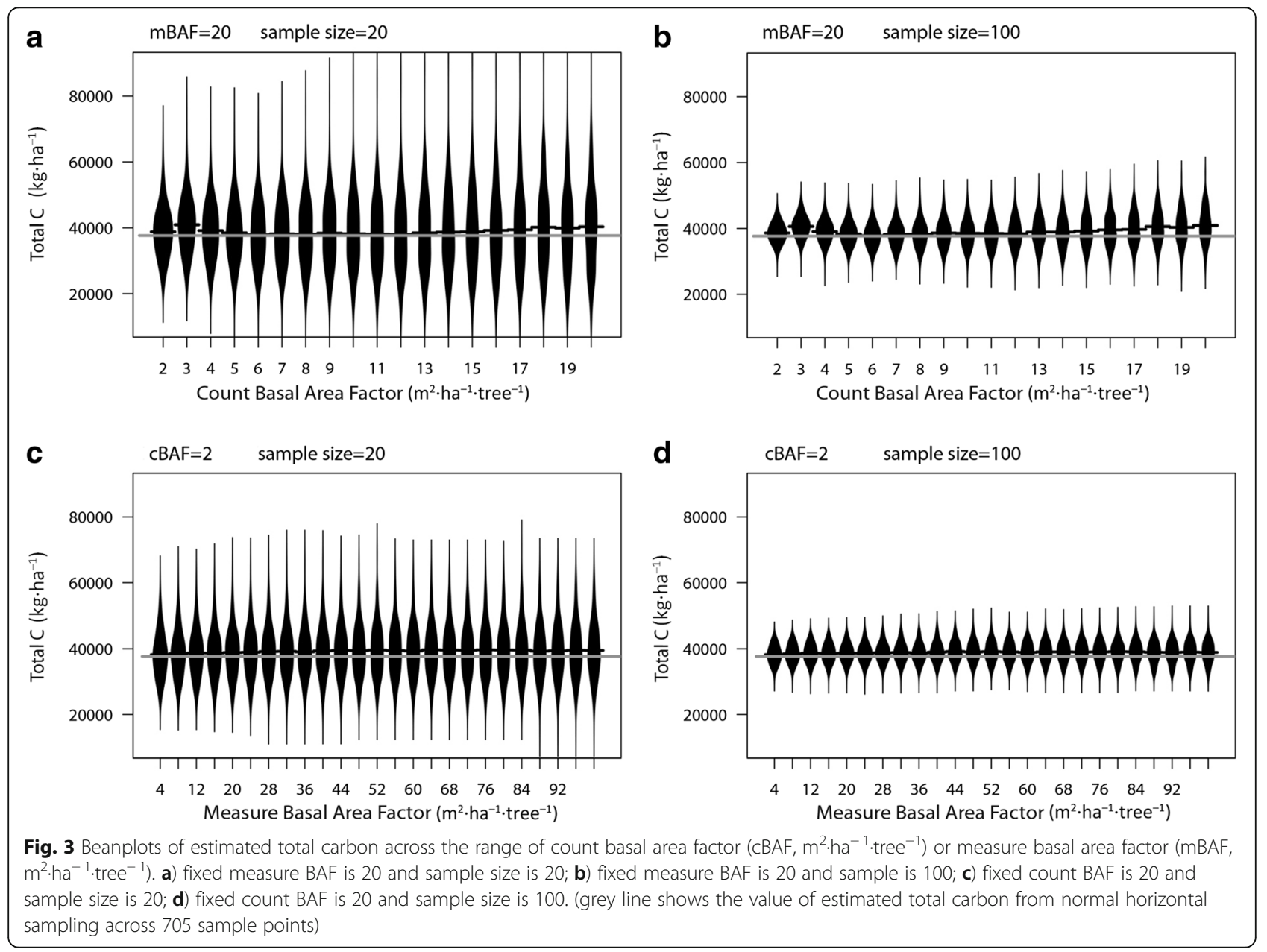




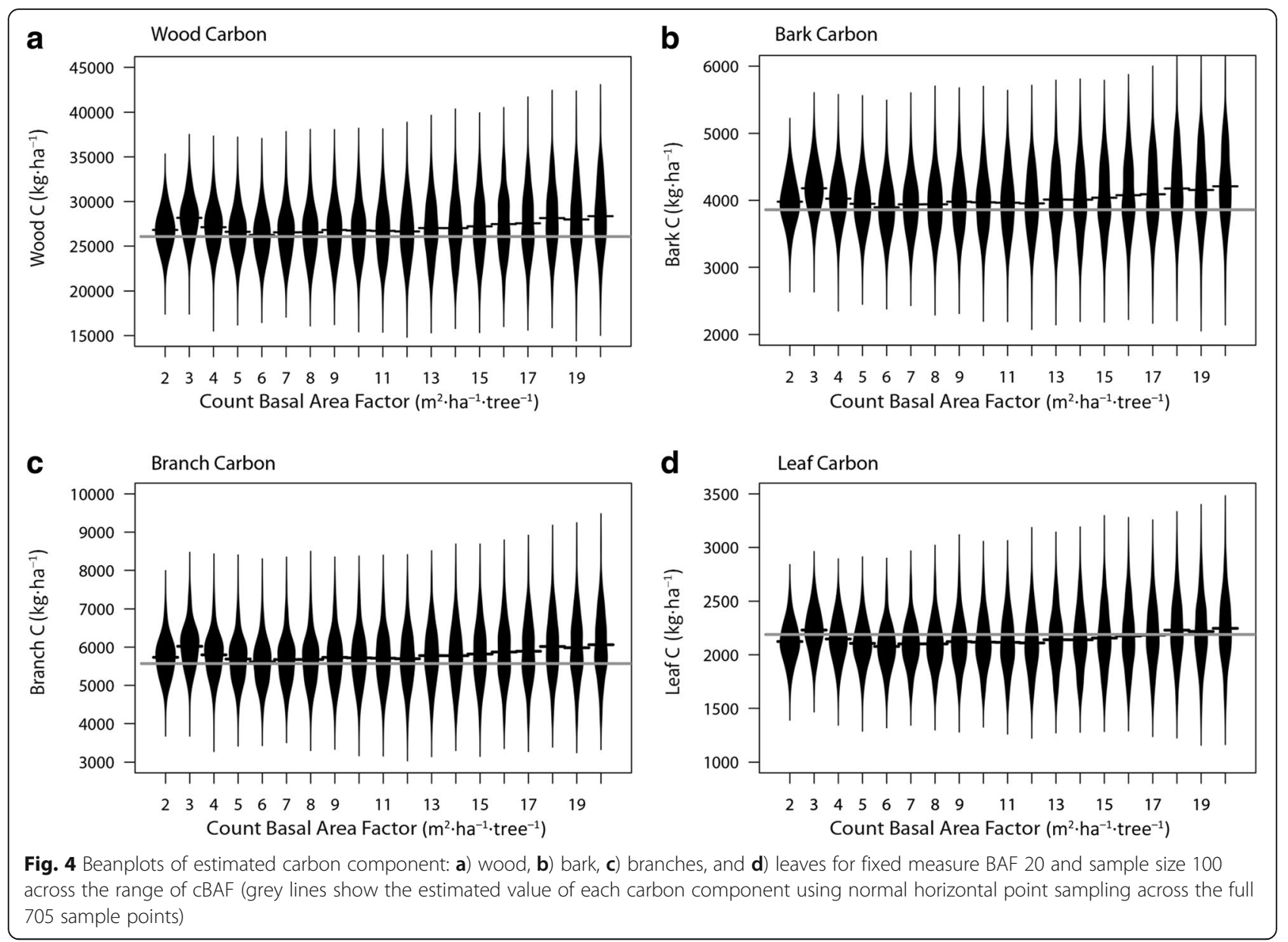

Table 1 Fixed effects parameter estimates (standard errors in parentheses) and associated regression statistics for Eq. 8 predicting SE\% given sample size and random effects associated with $\mathrm{CBAF}$ and $\mathrm{mBAF}$ nested within $\mathrm{cBAF}$

\begin{tabular}{lll}
\hline Factor & Parameter & \\
\cline { 2 - 3 } & $b_{0}$ & $b_{1}$ \\
\hline Fixed effects & $135.06(4.208)$ & -0.510 (0.0006) \\
RE (CBAF) & 22.6 & 0.003 \\
RE (mBAF within CBAF) & 1.1 & 0.005 \\
Fixed $R^{2}$ & 0.64 & \\
Random $R^{2}$ & & \\
$\quad$ CBAF & 0.83 & \\
mBAF within CBAF & 0.84 & \\
rMSE & 2.13 & \\
\hline
\end{tabular}

$\mathrm{RE}($ ) indicates the standard error associated with the random effects found for each of the 4 carbon components (Figs. 6 and 7). Higher cBAF led to higher SE\%, especially for branch and foliage (Fig. 6). Effects of mBAF are not apparent among the four components (Fig. 7), especially for wood and bark that had lower CV.

\section{Sample cost efficiency}

Figure 8 shows the inventory costs associated with different cBAFs, mBAFs, and stand basal areas. As cBAF increased, overall inventory costs (as estimated using Eq. 9) increased. Within each cBAF there was an optimal mBAF observed (Fig. 8a). The best combination of $\mathrm{cBAF} / \mathrm{mBAF}$ in this study was $2 / 24$. As basal area decreased, variability in counts increased, and associated inventory costs increased (Fig. 8b). As with increasing cBAF, each level of basal area had an optimal combination of $\mathrm{cBAF} / \mathrm{mBAF}$. The optimal mBAF increased with increasing stand basal area.

The design effects, expressed in terms of cost of inventory design 1 versus inventory design 2 showed trends similar to those observed in Fig. 8 for total cost (Additional file 1: Table S1). Design effects $<1$ indicated that the column design was superior to the row design. 

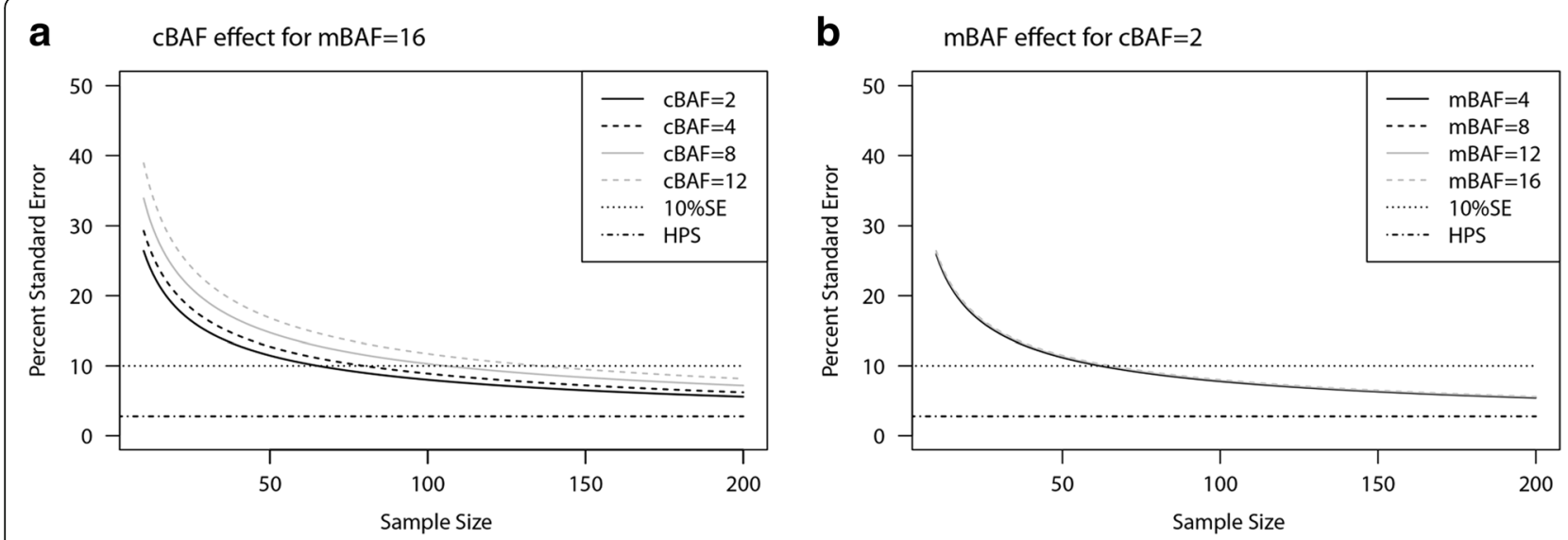

Fig. 5 Percent standard error for each sample size under a) different $\operatorname{cBAF}(2,4,8,12)$ with $\operatorname{mBAF}=16$ and $\mathbf{b})$ different $\mathrm{mBAF}(4,8,12,16)$ with $\mathrm{CBAF}=2$. HPS refers to the full Noonan inventory using normal horizontal point sample with a $2 \mathrm{M} B A F$
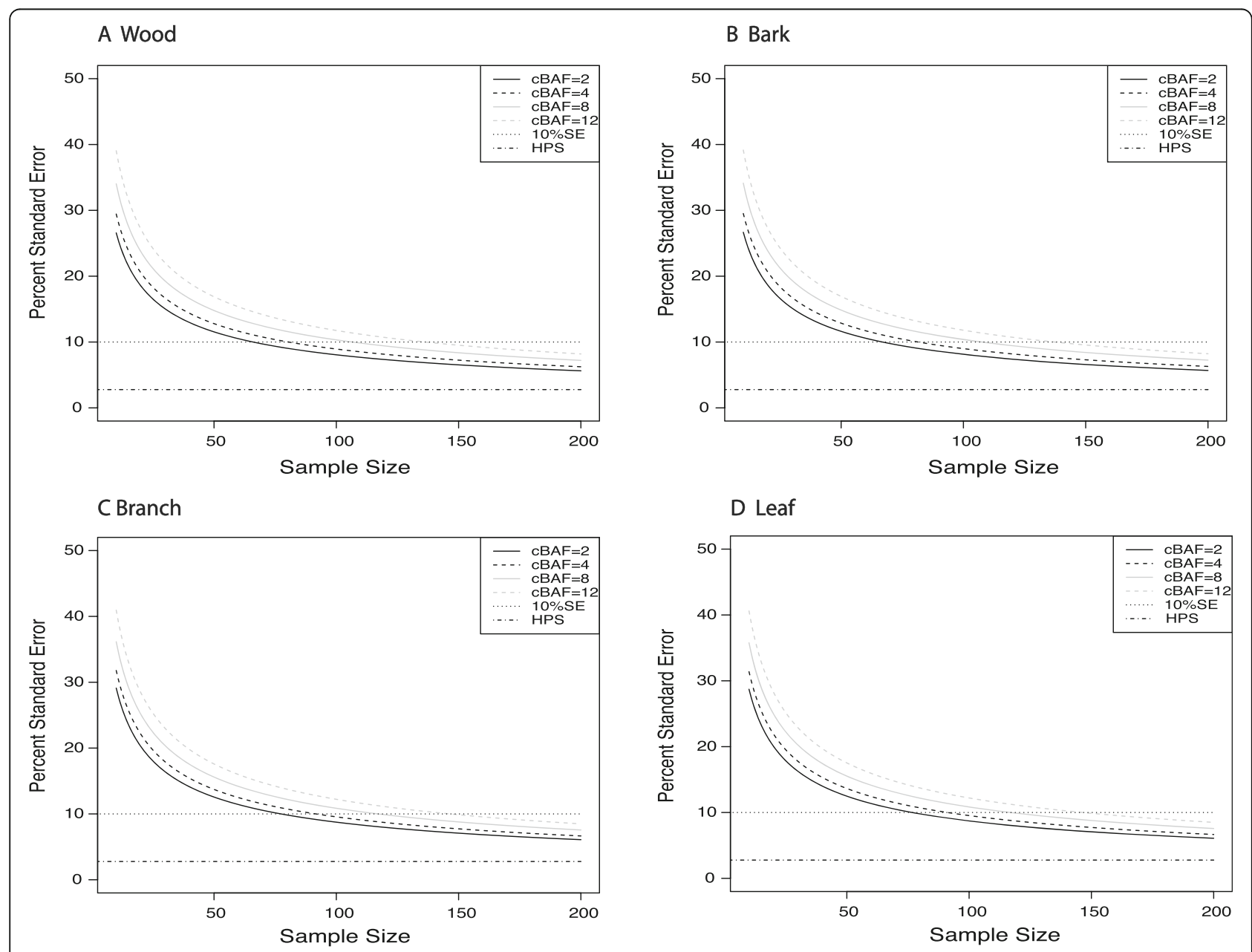

Fig. 6 Percent standard error for each sample size under different $\operatorname{cBAF}(2,4,8,12)$ with $m B A F=16$ for each carbon component a) wood, b) bark, c) branches, and d) leaves. HPS refers to the full Noonan inventory using normal horizontal point sample with a $2 \mathrm{M}$ BAF 

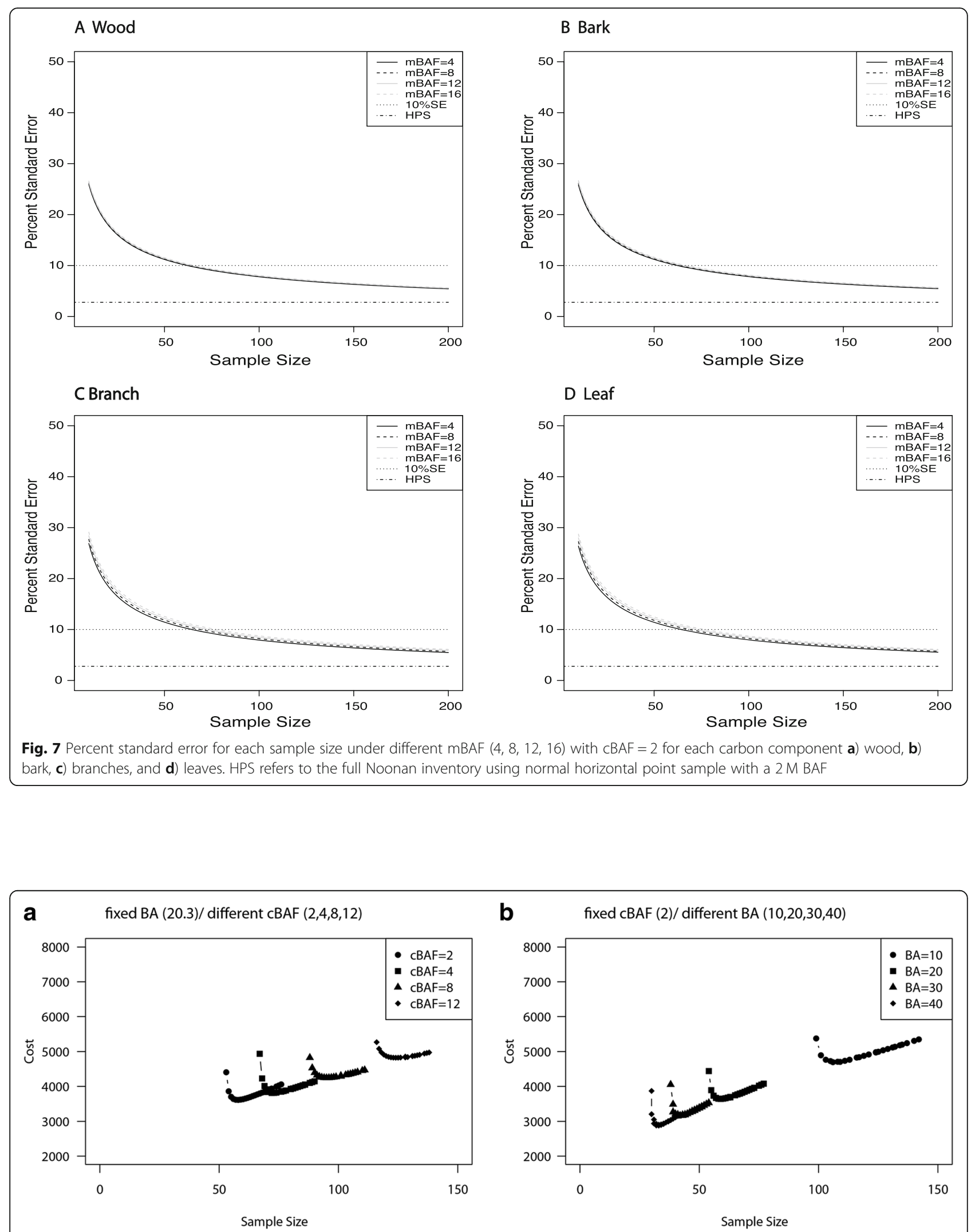

Fig. 8 Costs and minimum sample size for a) fixed stand BA/ha $\left(20.3 \mathrm{~m}^{2} \cdot \mathrm{ha}^{-1}\right)$ and different $\operatorname{CBAF}(2,4,8,12)$ and $\left.\mathbf{b}\right)$ fixed $\mathrm{cBAF}(2)$ with different stand BA/ha $\left(10,20,30,40 \mathrm{~m}^{2} \cdot \mathrm{ha}^{-1}\right)$ 
For each cBAF, design effect decreased with increasing mBAF up to some optimal mBAF, then increased slightly with increasing mBAF. As observed for total costs, the overall optimum cBAF/mBAF combination was $2 / 24$.

\section{Discussion}

The need for accurate carbon estimates is important for landowners wanting to enter monetized carbon markets (Radtke et al. 2017). A variety of sample designs have been used (Ravindranath and Ostwald 2008) and protocols for verifying and monitoring carbon offset programs established (Brown 1999). Inventory costs are often one of the barriers for many landowners (Charnley et al. 2010). Subsampling schemes are frequently used in forest inventories because they increase sample efficiency and decrease sample costs (Bell et al. 1983; Iles 2003; Kershaw et al. 2016). BigBAF sampling has been shown to be a very efficient sampling scheme for estimating volume (Desmarais 2002; Iles 2003; Marshall et al. 2004; Yang et al. 2017). Our results indicate that bigBAF sampling also is an effective sampling design for estimating carbon. Our optimal design using a $2 \mathrm{M} \mathrm{cBAF}$ and a $24 \mathrm{M}$ mBAF produced a standard error of $10 \%$ at a cost of approximately $\$ 3500$ Canadian, compared to the full Noonan inventory (the original 705 HPS plots with complete tree measurement) which cost about $\$ 40,000$ and produced an error of just less than $2 \%$.

The combination of cBAF and mBAF drives inventory costs (Yang et al. 2017). Understanding these effects is important when designing cost effective inventories. Optimal mBAF depended upon choice of cBAF (Fig. 8). Choosing an mBAF smaller than optimal had greater impacts on costs than choosing one larger. Our results indicate that the optimal sampling surface is very steep when expressed in terms of total inventory costs (Fig. 8). Lynch (2017) found that the cost - optimal plot size sample surface was very flat, suggesting that there was a lot of choice between numbers of plots and plot size that had little influence on overall cost efficiency; however, Yang et al. (2017) showed that optimum choice became more critical when inventory resources were limited. Given that we were focused on minimizing costs, our resulting sampling surface was steeper than what was observed in either Lynch (2017) or Yang et al. (2017).

In this study we did not consider stratified sampling because of the relatively uniform stand conditions across the NRF. Stratification is another sampling method that can reduce sample sizes (Iles 2003). Stratified sampling is most effective when the variation between strata is much larger than the variations within strata (Kershaw et al. 2016). In forests where stand origin, silviculture history, and site quality varies, stratified sampling can be an effective design and should be considered. Optimizing cBAF and
mBAF by strata could further increase sample efficiency and reduce costs.

Like Yang et al. (2017) found for CV (VBAR) (volume: basal area ratio), we found that $\mathrm{CV}$ (CBAR) was not influenced by increasing mBAF. Initially this might imply that increasing mBAF would always decrease costs; however, this was not what was observed (Fig. 8). As mBAF increases, the number of plots without a measure tree increases, and, at some point, overall sample size begins to increase in order to sample enough measure trees, thus increasing costs.

Costs are only one consideration in the overall inventory design. The results need to be accurate and free from substantial bias. As has been demonstrated elsewhere for volume (Marshall et al. 2004, Yang et al. 2017), bigBAF sampling for carbon produced consistent estimates of mean carbon with little or no bias across a wide range of cBAF, mBAF, and sample sizes (Figs. 3 and 4). When considering the components of carbon (Wood, Bark, Branches, and Leaf) CV (CBARS) were generally larger than for total carbon (Fig. 2). This increase in CV will increase inventory costs (Yang et al. 2017). For example, in this study, the estimation of leaf carbon would require, on average, about 4.5 times more plots than what are required for estimating total carbon. Estimation of the amounts of carbon in different pools is an important component of any carbon offset plan (Brown 2002), and can have huge impacts on the inventory costs associated with establishing baselines. We used allometric equations (Lambert et al. 2005) to obtain estimates of biomass that were then converted to carbon. Component ratios (Heath et al. 2009) have been shown to be less variable than the use of allometric equations (however, see the recent work by Zhao et al. (2018), which indicated that component ratio equation did not prove to be less variable than allometric equations for components). Incorporating a component ratio approach into our bigBAF sampling scheme may reduce the $\mathrm{CVs}$ associated with the various carbon components and reduce the costs required to estimate these at the accuracies required by carbon offset programs.

\section{Conclusions}

Big BAF sampling has been shown to be an effective sampling design for volume (Corrin 1998; Desmarais 2002; Marshall et al. 2004). We show that this efficiency can be extended to the estimation of carbon. Despite the known gains in efficiency, big BAF has only received moderate acceptance in operational forest inventories. The perceived efficiency already associated with horizontal point sampling may contribute to the slow adoption of bigBAF sampling in operational inventories (Yang et al. 2017). Our results demonstrate the potential impacts bigBAF can have 
on overall inventory costs. Producing accurate carbon estimates at a reduced cost minimizes one of the existing barriers for landowners considering entry into a carbon offset program. BigBAF sampling should be considered by landowners seeking a cost-effective inventory system for estimating carbon.

\section{Additional file}

Additional file 1: Table S1. Design effects for total inventory costs. $\mathrm{DE}=$ cost of column design / row design. $\mathrm{DE}<1$ means column design is more efficient, DE $>1$ means row design is more efficient. (XLSX $30 \mathrm{~kb}$ )

\section{Acknowledgements}

Marika Godman, Keith McHugh, Elizabeth McGarrigle, and David Thurrott were faithful and diligent summer/fall crew members. Without their work, this project would have been impossible.

\section{Funding}

Funding for this project was provide in part from the Natural Sciences and Engineering Research Council of Canada (Discovery Grant), the New Brunswick Innovation Foundation (Research Assistants Initiative), and the Research Affiliates Program, Natural Resources Canada.

\section{Availability of data and materials}

All data generated or analyzed during this study are included in this published article [and its Additional file].

\section{Authors' contributions}

YC was principle author and conducted most of the data analysis and figure development. TY and YH provided simulation code, feedback on written material and figures, and advice throughout the development of the manuscript. JAK provided funding and the data used in the simulation study as well as project guidance and additional $\mathrm{R}$ code. DP provided critical review of the overall manuscript and important insights into the struggles small woodlot owners have when trying to gain access to carbon and other new markets. All authors read and approved the final manuscript.

\section{Ethics approval and consent to participate}

Not applicable.

\section{Consent for publication}

Not applicable.

\section{Competing interests}

The authors declare that they have no competing interests.

\section{Author details}

${ }^{1}$ Faculty of Forestry and Environment Management, University of New Brunswick, PO Box 4400, Fredericton, NB E3B 5A3, Canada. ${ }^{2}$ Community Forests International, 10 School Lane, Sackville, NB E4L 3J9, Canada.

Received: 22 October 2018 Accepted: 28 February 2019

Published online: 10 April 2019

\section{References}

Bell JF, lles K, Marshall D (1983) Balancing the ratio of tree count-only sample points and VBAR measurements in variable plot sampling. In: Bell JF, Atterbury T (eds) Proceedings: Renewable Resource Inventories for Monitoring Changes and Trends. College of Forestry, Oregon State University, Corvallis, OR, pp 699-702

Brown SL (1999) Guidelines for inventorying and monitoring carbon offsets in forest-based projects

Brown SL (2002) Measuring, monitoring and verification of carbon benefits for forest-based projects. Philos Trans R Soc Lond A 360:1669-1683
Case BS, Hall RJ (2008) Assessing prediction errors of generalized tree biomass and volume equations for the boreal forest region of west-central Canada. Can J For Res 38:878-889

Charnley S, Diaz D, Gosnell H (2010) Mitigating climate change through smallscale forestry in the USA: opportunities and challenges. Small-Scale For 9: 445-462. https://doi.org/10.1007/s11842-010-9135-x

Corrin D (1998) BIG BAF: a very efficient sampling method for cruising timber. John Bell Assoc, p 43

Desmarais KM (2002) Using BigBAF sampling in a New England Mixedwood Forest. John Bell Assoc 58b

Elias M, Potvin C (2003) Assessing inter- and intra-specific variation in trunk carbon concentration for 32 neotropical tree species. Can J For Res 33:1039-1045

Goodman LA (1960) On the exact variance of products. J Am Stat Assoc 55:708. https://doi.org/10.2307/2281592

Heath LS, Hansen M, Smith JE, Smith WB, Miles PD (2009) Investigation into calculating tree biomass and carbon in the FIADB using a biomass expansion factor approach. In: McWilliams W, Moisen G, Czaplewski R. Forest Inventory and Analysis (FIA) Symposium 2008. Proceedings RMRS-P-56CD, Rocky Mountain Research Station, USDA, Forest Service, p 26

lles K (2003) A sampler of inventory topics, 2nd edn. Kim Iles and Associates, Nanaimo, BC

Kampstra P (2008) Beanplot: a boxplot alternative for visual comparison of distributions. J Stat Softw 28. https://doi.org/10.18637/jss.v028.c01

Kershaw JA Jr, Ducey MJ, Beers TW, Husch B (2016) Forest mensuration, fifth. Wiley/Blackwell

Lambert M-C, Ung C-H, Raulier F (2005) Canadian national tree aboveground biomass equations. Can J For Res 35:1996-2018

Lamlom SH, Savidge RA (2003) A reassessment of carbon content in wood: variation within and between 41 North American species. Biomass Bioenergy 25:381-388. https://doi.org/10.1016/S0961-9534(03)00033-3

Lynch TB (2017) Optimal plot size or point sample factor for a fixed total cost using the Fairfield Smith relation of plot size to variance. For Int J For Res 90: 211-218. https://doi.org/10.1093/forestry/cpw038

Marshall DD, lles K, Bell JF (2004) Using a large-angle gauge to select trees for measurement in variable plot sampling. Can J For Res 34:840-845

Radtke P, Walker D, Frank J et al (2017) Improved accuracy of aboveground biomass and carbon estimates for live trees in forests of the eastern United States. Forestry 90:32-46. https://doi.org/10.1093/forestry/cpw047

Ravindranath NH, Ostwald M (2008) Carbon inventory methods: handbook for greenhouse gas inventory, carbon mitigation and roundwood production projects. Springer, New York

Rice B, Weiskittel AR, Wagner RG (2014) Efficiency of alternative forest inventory methods in partially harvested stands. Eur J For Res 133:261-272

Russell-Roy ET, Keeton WS, Pontius JA, Kerchner CD (2014) Rehabilitation forestry and carbon market access onhigh-graded northern hardwood forests. Can J For Res 44:614-627. https://doi.org/10.1139/cjfr-2013-0437

Särndal C-E, Swensson B, Wretman J (1992) Model assisted survey sampling, 1st edn. Springer-Verlag, New York

Yang T-R, Hsu Y-H, Kershaw JA Jr et al (2017) Big BAF sampling in mixed species forest structure of northeastern North America: influence of count and measure BAF under cost constraints. Forestry 90:649-660

Zhao D, Westfall J, Coulston JW et al (2018) Additive biomass equations for slash pine trees: comparing three modeling approaches. Can J For Res:27-40. https://doi.org/10.1139/cjfr-2018-0246 